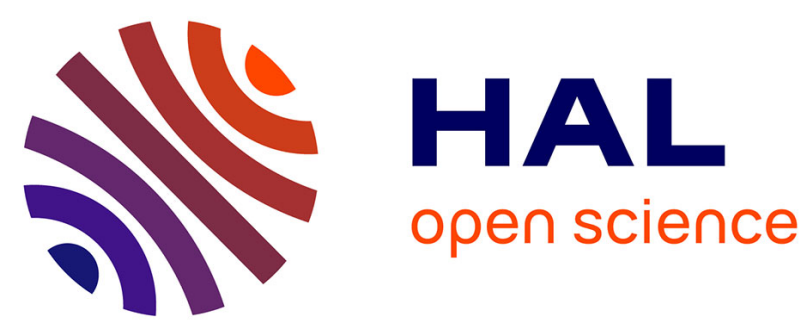

\title{
Optimization and Gram-Scale Preparation of S -Trifluoromethyl Sulfoximines and Sulfilimino Iminiums, Powerful Reagents for the Late Stage Introduction of the CF 3 Group
}

Anne-Laure Barthelemy, Victor Certal, Guillaume Dagousset, Elsa Anselmi, Luc Bertin, Laurence Fabien, Bruno Salgues, Philippe Courtes, Christian Poma, Youssef El-Ahmad, et al.

\section{- To cite this version:}

Anne-Laure Barthelemy, Victor Certal, Guillaume Dagousset, Elsa Anselmi, Luc Bertin, et al.. Optimization and Gram-Scale Preparation of S -Trifluoromethyl Sulfoximines and Sulfilimino Iminiums, Powerful Reagents for the Late Stage Introduction of the CF 3 Group. Organic Process Research and Development, 2020, 24 (5), pp.704-712. 10.1021/acs.oprd.9b00403 . hal-03097860

\author{
HAL Id: hal-03097860 \\ https://hal.science/hal-03097860
}

Submitted on 5 Jan 2021

HAL is a multi-disciplinary open access archive for the deposit and dissemination of scientific research documents, whether they are published or not. The documents may come from teaching and research institutions in France or abroad, or from public or private research centers.
L'archive ouverte pluridisciplinaire HAL, est destinée au dépôt et à la diffusion de documents scientifiques de niveau recherche, publiés ou non, émanant des établissements d'enseignement et de recherche français ou étrangers, des laboratoires publics ou privés. 


\section{Optimization and Gram-scale Preparation of S-}

\section{Trifluoromethyl- Sulfoximines and Sulfilimino}

\section{iminiums, Powerful Reagents for the Late Stage}

\section{Introduction of the $\mathrm{CF}_{3}$ Group}

Anne-Laure Barthelemy, ${ }^{1}$ Victor Certal, ${ }^{2}$ Guillaume Dagousset, ${ }^{1}$ Elsa Anselmi, ${ }^{1}$ Luc Bertin, ${ }^{2}$ Laurence Fabien, ${ }^{2}$ Bruno Salgues, ${ }^{2}$ Philippe Courtes, ${ }^{2}$ Christian Poma, ${ }^{2}$ Youssef El-Ahmad $* 2$ and Emmanuel Magnier ${ }^{* 1}$

1) Institut Lavoisier de Versailles (ILV), UMR CNRS 8180, Université de Versailles, St Quentin en Yvelines, 45 av. des Etats-Unis, 78035 Versailles Cedex, France.

2) SANOFI, Centre de Recherche de Vitry/Alfortville, 13, quai Jules Guesde - BP 14 - 94403

Vitry-sur-Seine Cedex France.

emmanuel.magnier@uvsq.fr

ORCID :

Anne-Laure Barthelemy : orcid.org/0000-0003-2789-676X

Guillaume Dagousset: orcid.org/0000-0001-8720-3828

Elsa Anselmi : orcid.org/0000-0003-2996-2775

Emmanuel Magnier : orcid.org/0000-0003-3392-3971 


\section{TOC Graphic}

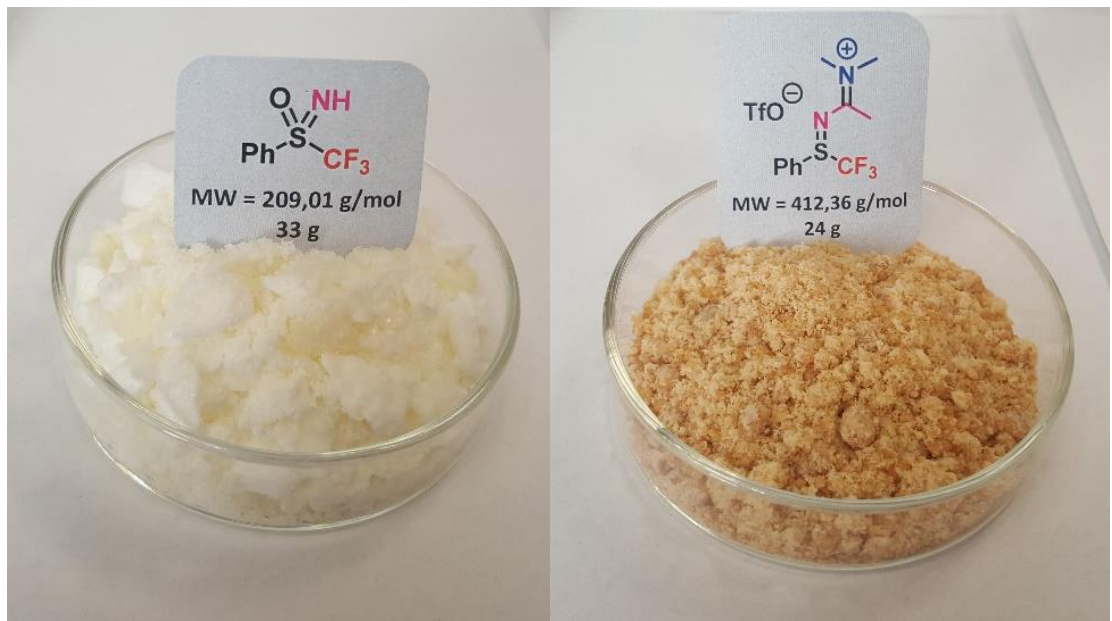

Multigram synthesis of sulfoximine $\mathbf{4}$ and sulfilimino iminium $\mathbf{5}$ 
ABSTRACT: $S$-trifluoromethyl sulfoximine and $S$-trifluoromethyl sulfilimino iminiums are important reagents for the electrophilic or radical late-stage introduction of the $\mathrm{CF}_{3}$ group. We disclose in this article a reappraisal of our previous methodologies and their adaptation to a large scale. More than $30 \mathrm{~g}$ of the key sulfoximine 4 and $40 \mathrm{~g}$ of $S$-trifluoromethyl sulfilimino iminium 5 are prepared without purification. DSC measurements have been performed on both the crude mixture and the isolated compounds in order to insure a safe process. The cost of the synthesis is also detailed and discussed.

KEYWORDS: Trifluoromethyl, Sulfoximines, Sulfilimino iminiums, Sulfilimines, DSC measurements.

\section{INTRODUCTION}

The introduction of a fluorine atom or perfluoroalkylated moieties into an organic compound can lead to profound changes in its physical, chemical or biological properties due to the peculiar intrinsic properties of the fluorine atom. ${ }^{1}$ Indeed, fluorine exhibits a high electronegativity (4.0 on the Pauling scale), a small atomic radius (1.47 $\AA$ ) and induces a strong C-F bond (about 116 $\mathrm{kcal} / \mathrm{mol}$ ). This is the reason why nowadays about $20 \%$ of pharmaceuticals and $50 \%$ of agrochemical compounds contain at least one fluorine atom. ${ }^{2}$ However, the number of natural organic compounds containing a fluorinated moiety is quite limited. ${ }^{3}$ This implies that access to organofluorine compounds is essentially based on the development of practical fluorination or fluoroalkylation reactions, and always requires new methodologies. The toolbox that chemists now possess contains more and more fluorinating and perfluoroalkylating reagents which are stable, selective and easy to handle. Among them, the electrophilic reagents of Umemoto and Togni (Figure 1) have probably been the most popular. ${ }^{4}$ In addition, a third class of compounds in this family, the fluorinated sulfoximines, should not be omitted and have received increasing attention 
in the last decade. ${ }^{5}$ Indeed, these aza-analogs of sulfones are fluoroalkylating reagents with flexible reactivity, via nucleophilic, electrophilic or radical pathways. The Shibata reagent is the most known member of this family, but in our laboratory, we have also discovered other types of sulfoximine-based reagents as well as a very peculiar structure, a sulfilimino iminium, which has successfully been used for the efficient production of the trifluoromethyl radical. ${ }^{6}$

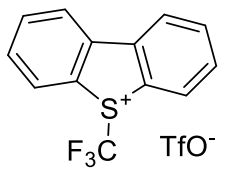

Umemoto reagent

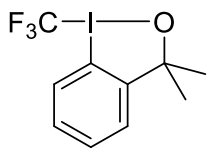

Togni reagents

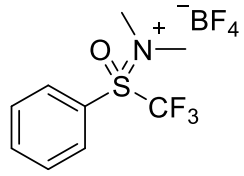

Shibata reagent

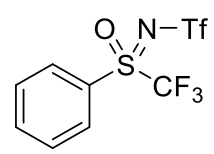

sulfoximine

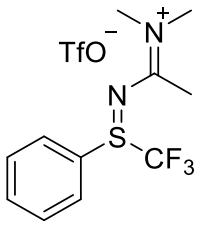

sulfilimino iminium

Figure 1: Electrophilic or radical perfluoroalkylating reagents

The synthesis of NH $S$-perfluoroalkylated sulfoximines was quite cumbersome, using harsh and dangerous conditions, until our group described, in 2009, a three-step methodology for the preparation of such compounds. ${ }^{7}$ A slight adaptation of the reaction conditions allowed access to sulfilimino iminiums.

Consequently, because of the increasing use of sulfoximines as reagents, large-scale production appeared to be essential. We describe in this article a gram-scale, divergent synthesis of sulfoximine and sulfilimino iminium. Each step of our previous methodologies has been reconsidered and improved. Differential Scanning Calorimetry (DSC) measurements of both the reaction mixtures and the isolated molecules are described in order to ensure the maximum safety of the process. Total costs of the synthesis are also discussed.

\section{RESULTS AND DISCUSSION}

The synthesis of these reagents starts from the phenyl trifluoromethyl sulfoxide $\mathbf{1}$, which is treated with acetonitrile in the presence of triflic anhydride, leading, via a Ritter-type reaction, to 
a putative bis-triflate intermediate 2 (Scheme 1). This intermediate, stable at $-15^{\circ} \mathrm{C}$, can further evolve by two different pathways: i) hydrolysis of the reaction gives the $N$-acetylated intermediate sulfilimine 3, which can be smoothly oxidized by $\mathrm{KMnO}_{4}$ and deprotected in the presence of $6 \mathrm{M}$ $\mathrm{HCl}$ to obtain the trifluoromethylated sulfoximine 4 ; ii) addition of a secondary amine to intermediate $\mathbf{2}$ directly leads to the sulfilimino iminium $\mathbf{5}$.

Scheme 1: Synthetic scheme of the preparation of trifluoromethyl- sulfoximines and sulfilimino iminiums

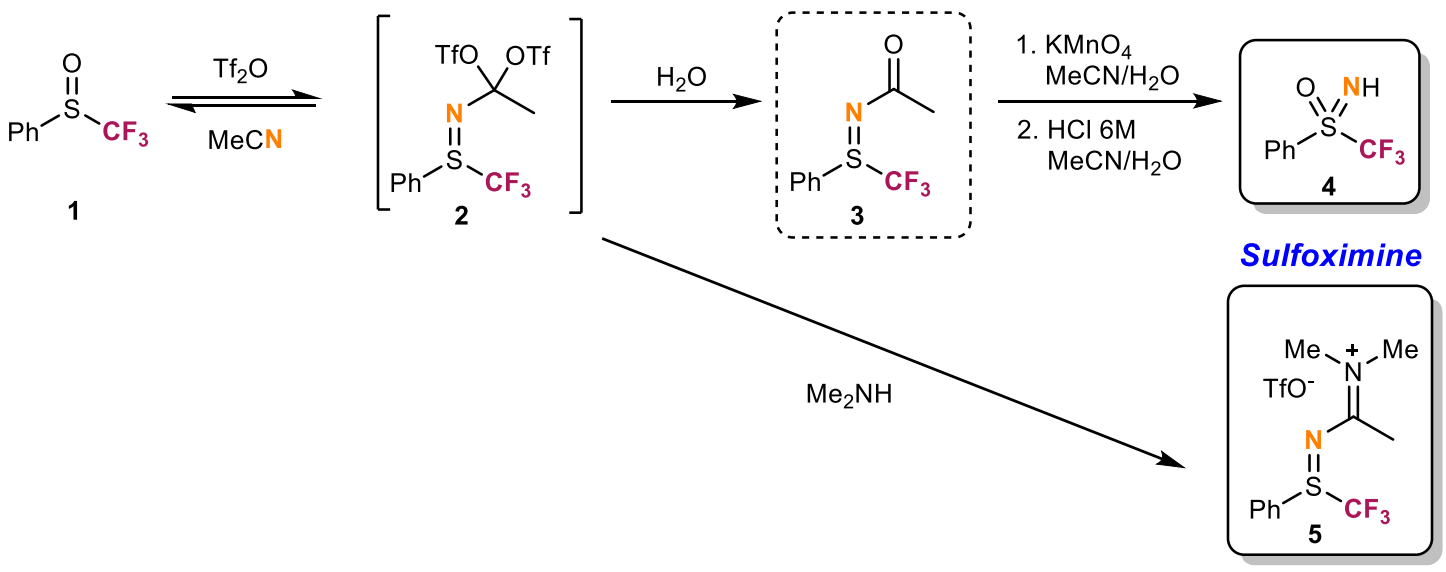

Sulfilimino iminium

\section{Synthesis of the phenyl trifluoromethyl sulfoxide 1.}

The phenyl trifluoromethyl sulfoxide $\mathbf{1}$ is commercially available but quite expensive (at least $78 €$ per gram). However, compound $\mathbf{1}$ can be easily prepared following our previously described one-pot procedure starting from sodium trifluoromethanesulfinate (Langlois reagent) and benzene. ${ }^{8}$ A reappraisal of our protocol is presented herein (Scheme 2). The production of compound 1 has been scaled up to $78 \mathrm{~g}$ without major issues and with a good yield of $73 \%$ (Table 1 , entry 3 ) after purification by distillation.

Scheme 2: Synthesis of the sulfoxide 1 


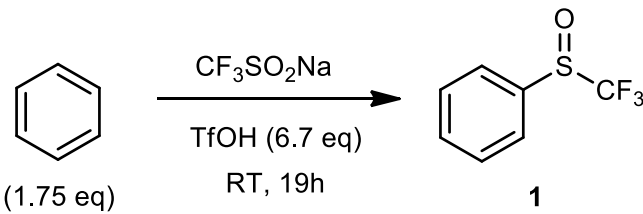

This reaction occurs without solvent which causes two major issues: elevation of the temperature of the reaction and difficulty in stirring the reaction mixture. It is noteworthy that the addition of trifluoromethanesulfonic acid to sodium trifluoromethanesulfinate leads to a pasty mixture and to a rapid increase in temperature that can rise to $80^{\circ} \mathrm{C}$. On a $10 \mathrm{~g}$ scale (Table 1 , entry 1 ), magnetic stirring gives a reasonably homogeneous mixture and the exothermic phenomenon is not problematic. With larger quantities of reagents (Table 1, entries 2-3), mechanical stirring is required to obtain good dispersion and a homogeneous medium. Otherwise, the formation of aggregates proves deleterious to the yield. The triflic acid should be added portion wise (at least by thirds) to minimize temperature elevation. An additional cold-water bath is required to maintain the temperature of the reaction mixture (controlled by a thermometer) below $50^{\circ} \mathrm{C}$. After 19 hours of stirring at room temperature, the reaction is poured onto ice $(10 \mathrm{~g}$ of ice for $1 \mathrm{~g}$ of sodium trifluoromethanesulfinate) to control the exothermicity of the quenching.

Table 1: Multigram synthesis of phenyl trifluoromethyl sulfoxide 1

\begin{tabular}{cccccc}
\hline Entry & Benzene & $\mathbf{C F}_{3} \mathbf{S O}_{2} \mathbf{N a}$ & TfOH & Sulfoxide & Yield \\
\hline $\mathbf{1}$ & $10 \mathrm{~mL}$ & $10 \mathrm{~g}$ & $35 \mathrm{~mL}$ & $7.6 \mathrm{~g}$ & $61 \%$ \\
$\mathbf{2}^{\mathrm{a}}$ & $50 \mathrm{~mL}$ & $50 \mathrm{~g}$ & $176 \mathrm{~mL}$ & $41.9 \mathrm{~g}$ & $68 \%$ \\
$\mathbf{3}^{\mathrm{a}}$ & $90 \mathrm{~mL}$ & $90 \mathrm{~g}$ & $315 \mathrm{~mL}$ & $78.1 \mathrm{~g}$ & $73 \%$ \\
\hline
\end{tabular}

a Use of a mechanical stirrer 
The thermal stability of this compound was explored by DSC analysis (Figure 2). The phenyl trifluoromethyl sulfoxide $\mathbf{1}$ exhibits good thermal stability with decomposition from $205^{\circ} \mathrm{C}$, proving the safety of the previously described reaction conditions and purification.

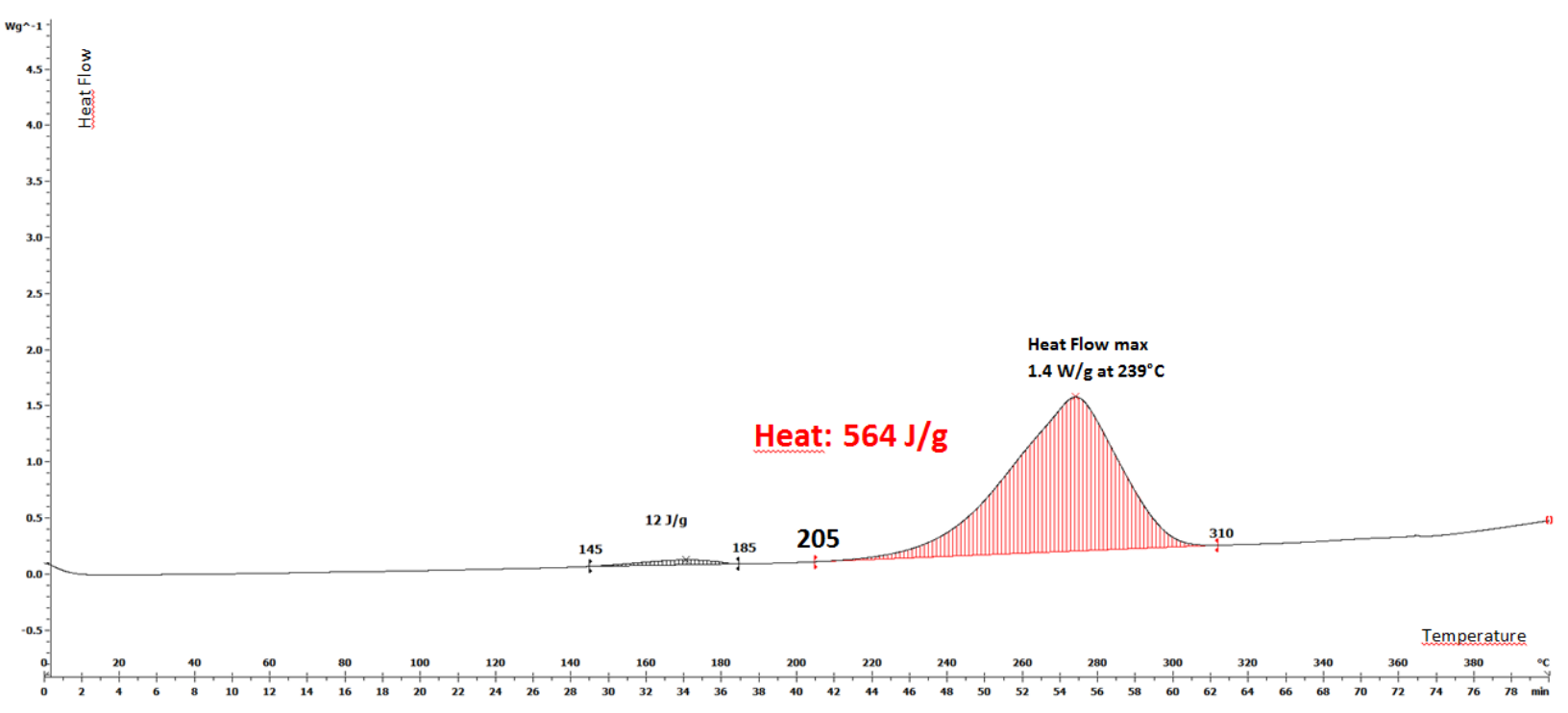

Figure 2: DSC analysis of the phenyl trifluoromethyl sulfoxide 1

It is important to underline that purification of the sulfoxide $\mathbf{1}$ is not necessary for the next steps.

\section{Synthesis of the intermediary sulfilimine 3 .}

The second step is a Ritter-type reaction between the sulfoxide $\mathbf{1}$ and acetonitrile in the presence of trifluoromethanesulfonic anhydride. The procedure described by our group in $2009^{7 \mathrm{a}}$ has been adapted to a larger scale using acetonitrile as reagent and solvent, increasing its quantity from 1.5 to 11 equivalents.

Scheme 3: Synthesis of the intermediary sulfilimine 3 
<smiles>O=S(c1ccccc1)C(F)(F)F</smiles>

1

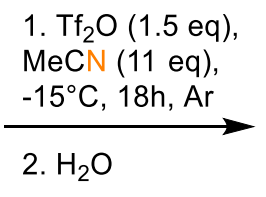

2. $\mathrm{H}_{2} \mathrm{O}$<smiles>CC(F)(F)C(F)(F)F</smiles>

3

It should be noticed that a low temperature $\left(-15^{\circ} \mathrm{C}\right)$ is necessary to control the first step and to obtain an optimal formation of the intermediate sulfilimine 3. This experimental observation was supported by DSC analysis of the reaction media just after the addition of trifluoromethanesulfonic anhydride and also after full conversion of the sulfoxide $\mathbf{1}$. The DSC analysis of the reaction medium after the dropwise addition of trifluoromethanesulfonic anhydride $\left(\mathrm{Tf}_{2} \mathrm{O}\right)$ shows an endothermic peak at $20^{\circ} \mathrm{C}$ followed by an exothermic peak from $55^{\circ} \mathrm{C}$, revealing the instability of the reaction medium (Figure 3). Moreover, after full conversion of sulfoxide 1, it was shown that the medium is quite unstable with an exothermic peak starting at $15^{\circ} \mathrm{C}$ (Figure 4). Therefore, the temperature of the reaction should be maintained under $-15^{\circ} \mathrm{C}$ to preserve an acceptable thermal stability. For this purpose, the reaction can be simply stored in a freezer for 18 hours, as the absence of stirring does not negatively impact the yield of the transformation.

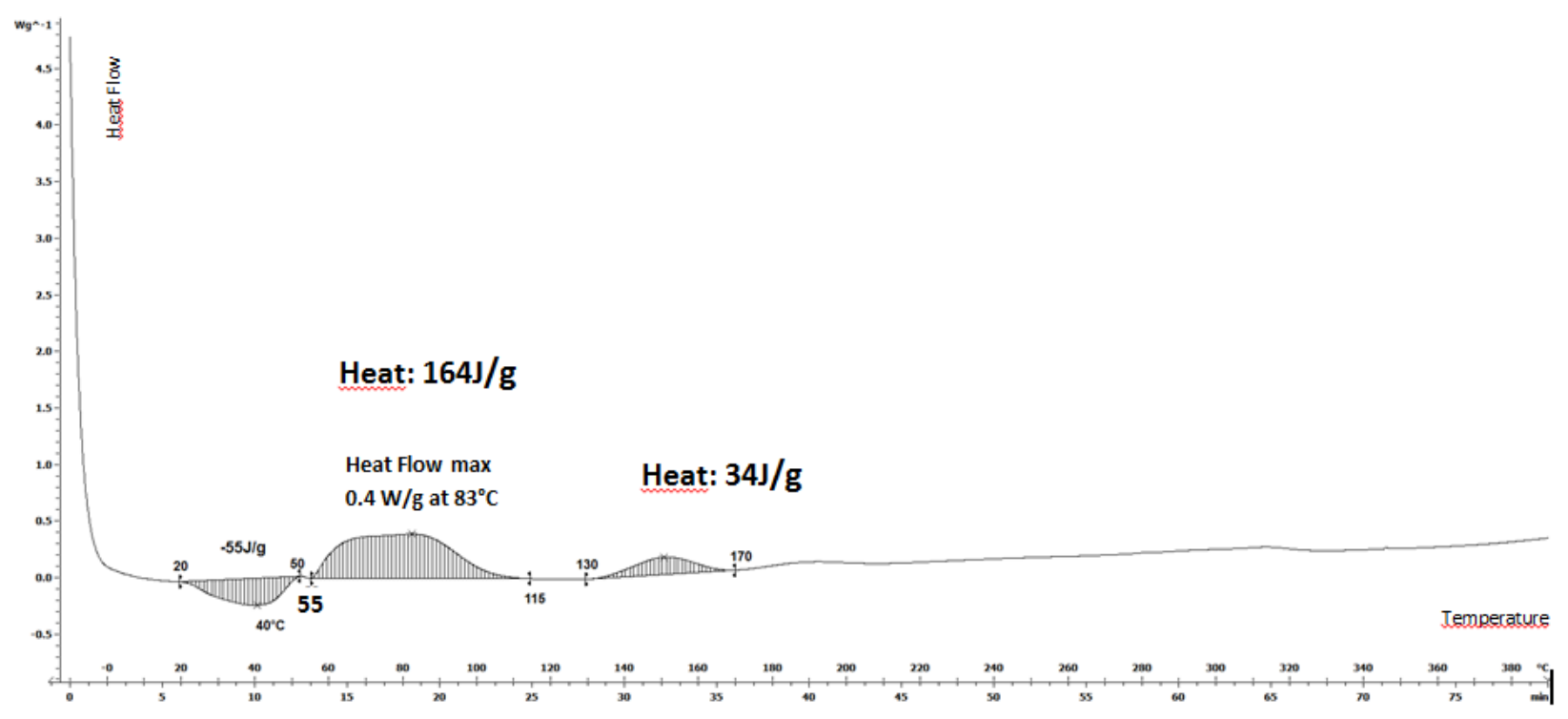

Figure 3: DSC analysis of the reaction medium after the addition of $\mathrm{Tf}_{2} \mathrm{O}$ 


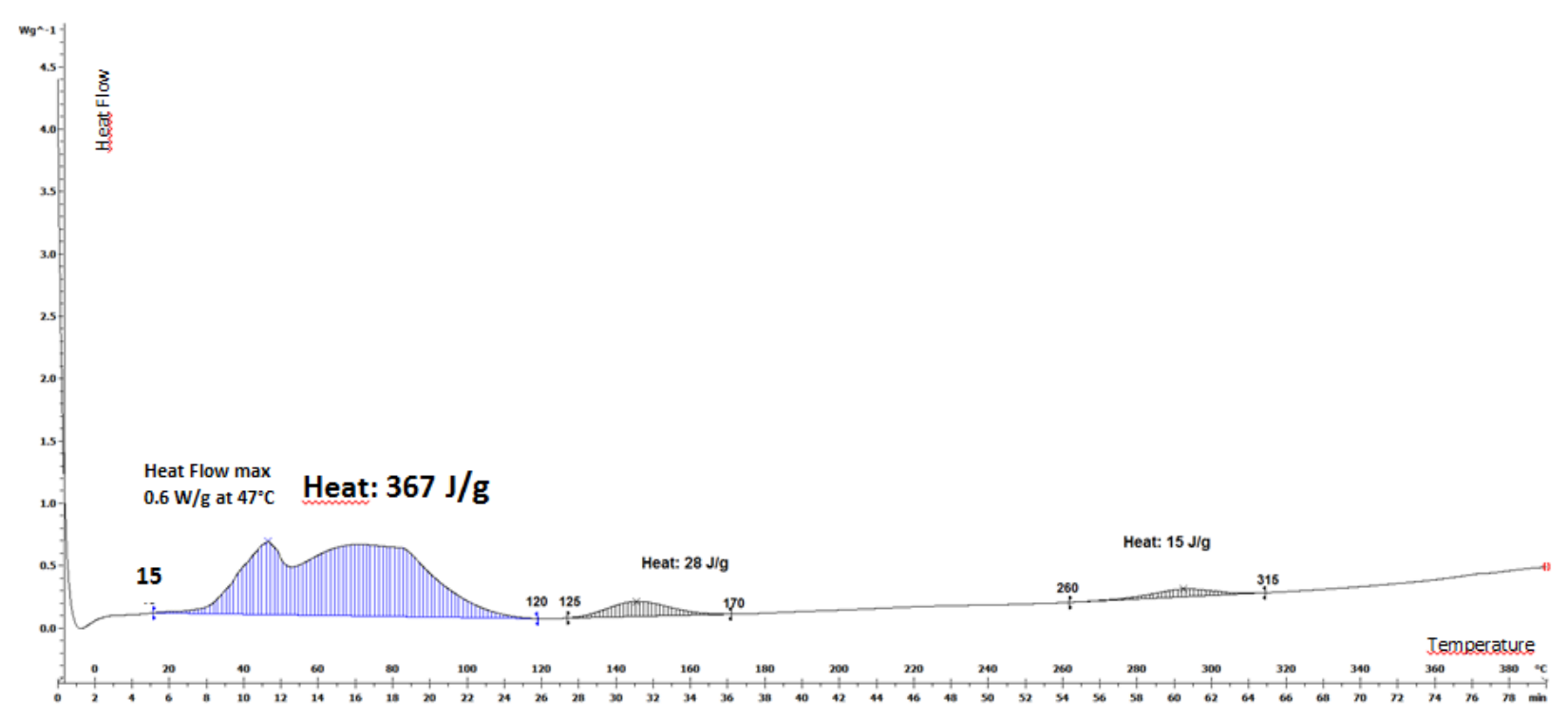

Figure 4: DSC analysis at full conversion of sulfoxide 1

It should be underlined that there is an interaction between triflic anhydride $\mathrm{Tf}_{2} \mathrm{O}$ and acetonitrile (Figure 5), regardless of the number of equivalents, with a thermal phenomenon, which contributes to the one of the reaction (Figure 4).

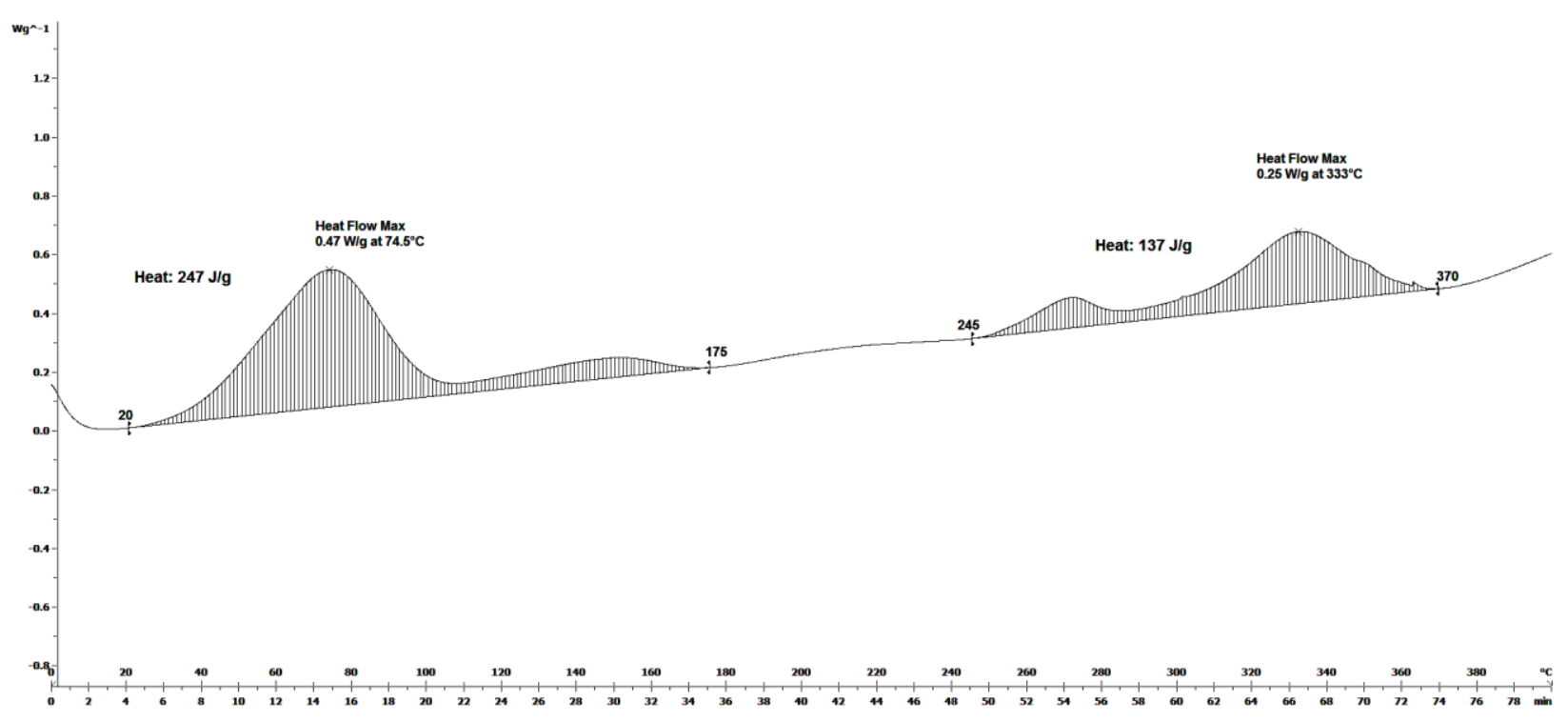

Figure 5: DSC analysis of the interaction between $\mathrm{Tf}_{2} \mathrm{O}$ and acetonitrile $\left(\mathrm{Tf}_{2} \mathrm{O} / \mathrm{MeCN}=1 / 2 \mathrm{v} / \mathrm{v}\right)$ 
In our initial publication, ${ }^{7 \mathrm{a}}$ water was directly added to the reaction mixture. On a larger scale and in order to control the exothermicity of the reaction quench, it is necessary to pour the crude mixture onto ice (10 $\mathrm{g}$ of ice for $1 \mathrm{~g}$ of sulfoxide $\mathbf{1})$. The pure $N$-acetylated sulfilimine $\mathbf{3}$ shows a DSC profile with a decomposition starting from an onset temperature of $145^{\circ} \mathrm{C}$ (Figure 6), far from the process temperature.

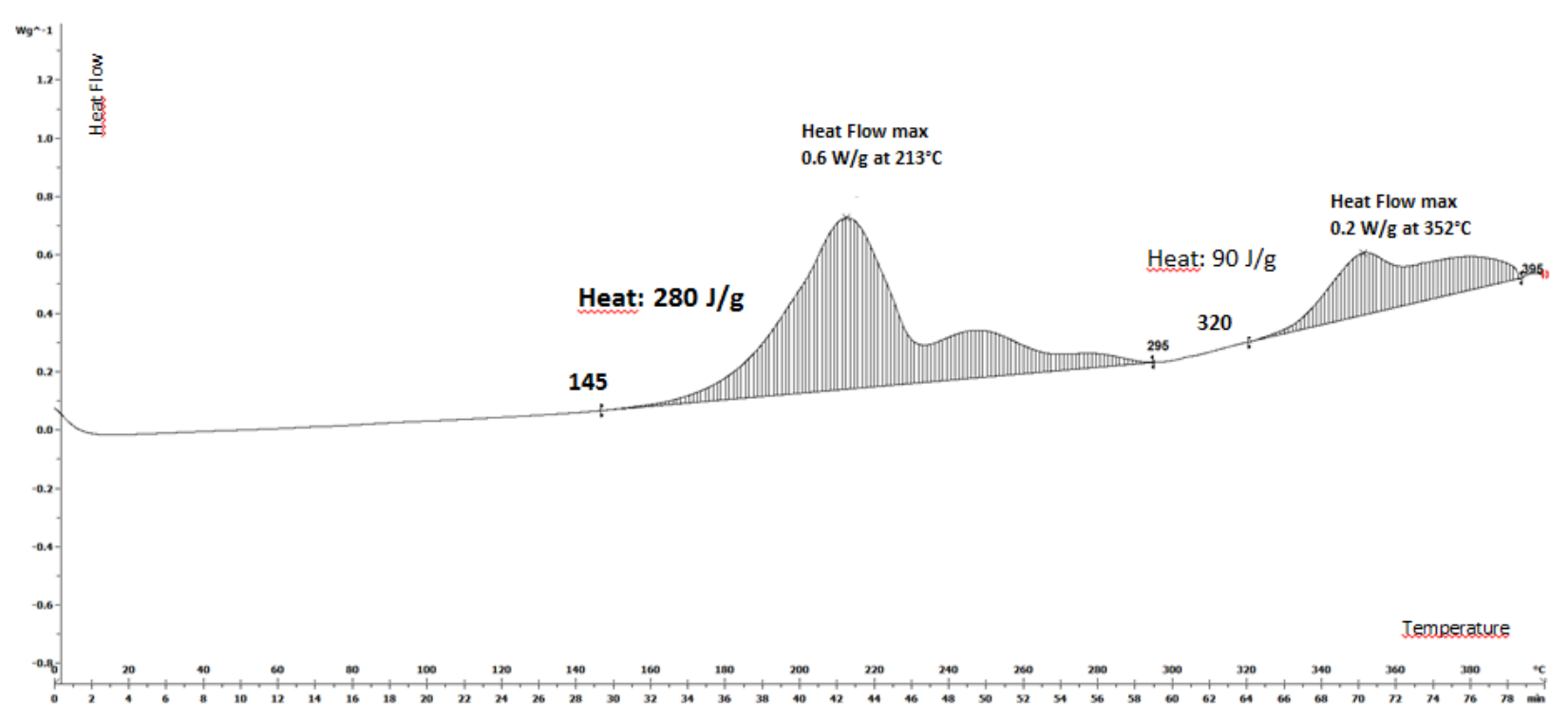

Figure 6: DSC analysis of the N-acetylated sulfilimine 3

\section{Synthesis of the trifluoromethyl sulfoximine 4.}

The sulfilimine $\mathbf{3}$ is then smoothly oxidized in the presence of potassium permanganate in dilute medium and the obtained acetylated sulfoximine $\mathbf{4}^{\prime}$ is deprotected with hydrochloric acid to give the sulfoximine 4.

Scheme 4: Synthesis of the sulfoximine 4<smiles></smiles>

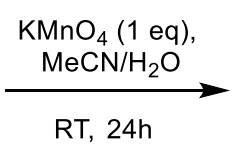<smiles>O=S(=O)(c1ccccc1)c1ccccc1</smiles>

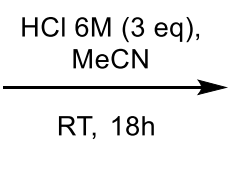<smiles>NS(=O)(=O)c1ccccc1</smiles>

On a large scale, an excellent overall yield is obtained for the production of $33 \mathrm{~g}$ of sulfoximine 4 (Table 2, entry 3). The scale up can be achieved without major issues. To facilitate the oxidation 
step on scale-up, potassium permanganate was slowly added as a solid to the solution of intermediate sulfilimine $\mathbf{3}$ in water and acetonitrile. It is important to note that no intermediate purification is required and the final product was simply filtered through a pad of silica. Pleasingly, we noticed a substantial improvement in the yield on increasing the scale of the reaction.

Table 2: Multigram synthesis of phenyl trifluoromethyl sulfoximine 4

\begin{tabular}{cccccccc}
\hline Entry & Sulfoxide & $\mathbf{T f}_{2} \mathbf{O}$ & $\mathbf{M e C N}$ & $\mathrm{KMnO}_{4}$ & HCl 6M & Sulfoximine & Yield \\
\hline $\mathbf{1}$ & $5 \mathrm{~g}$ & $6.5 \mathrm{~mL}$ & $15 \mathrm{~mL}$ & $4.07 \mathrm{~g}$ & $8.4 \mathrm{~mL}$ & $2.7 \mathrm{~g}$ & $50 \%$ \\
$\mathbf{2}$ & $20 \mathrm{~g}$ & $26 \mathrm{~mL}$ & $60 \mathrm{~mL}$ & $16.28 \mathrm{~g}$ & $33.6 \mathrm{~mL}$ & $14.3 \mathrm{~g}$ & $66 \%$ \\
$\mathbf{3}$ & $40 \mathrm{~g}$ & $52 \mathrm{~mL}$ & $120 \mathrm{~mL}$ & $32.56 \mathrm{~g}$ & $67.2 \mathrm{~mL}$ & $32.8 \mathrm{~g}$ & $76 \%$ \\
\hline
\end{tabular}

Both steps were analyzed by DSC. The oxidation medium exhibits an exothermic peak from $125^{\circ} \mathrm{C}$, revealing a good thermal stability of the mixture (Figure 7) under the reaction conditions.

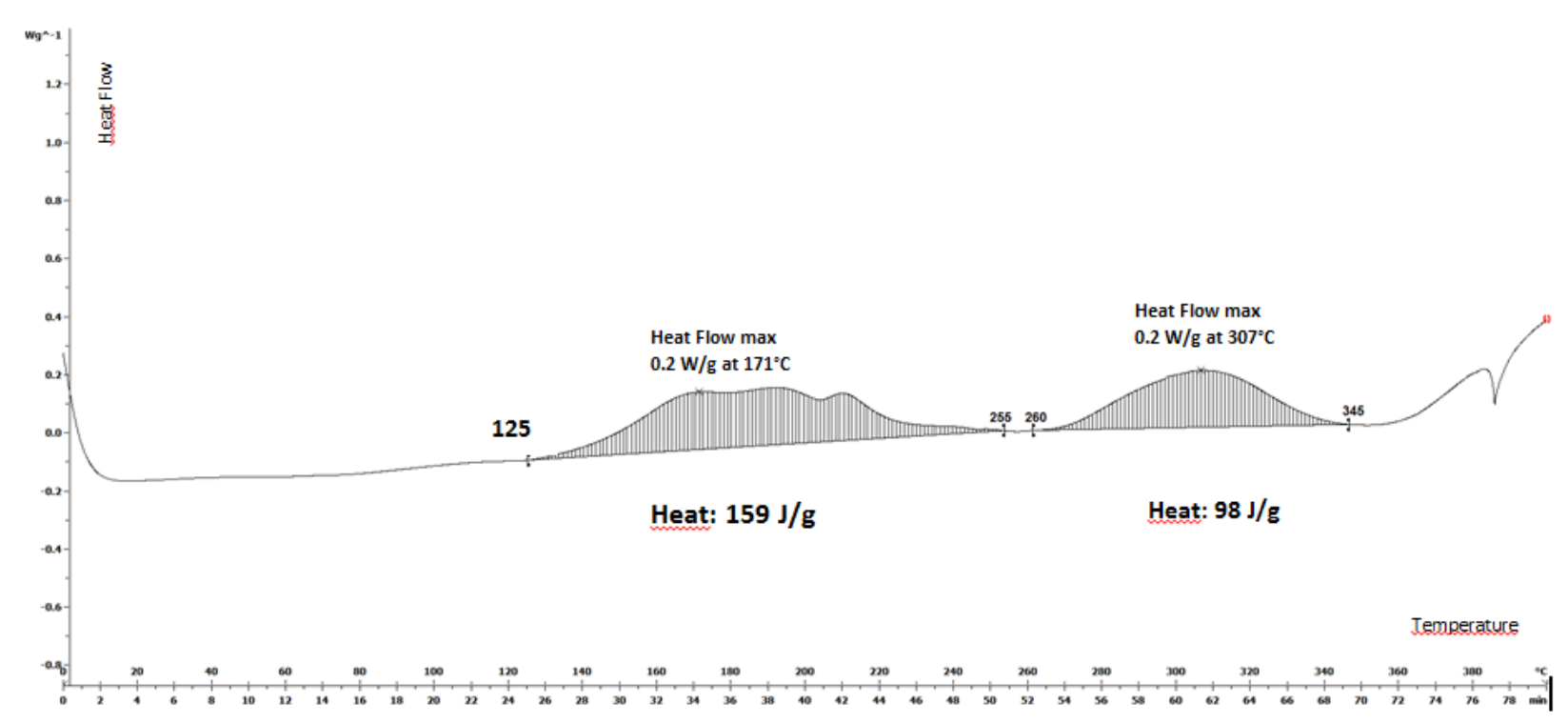

Figure 7: DSC analysis of the oxidation reaction medium 
The hydrolysis of the intermediate N-protected sulfoximine 4' medium also possesses a good thermal stability with an exothermic peak starting at $225^{\circ} \mathrm{C}$ (Figure 8). A slight exothermic decomposition appears from $115^{\circ} \mathrm{C}$ but presents no notable risk under the reaction conditions.

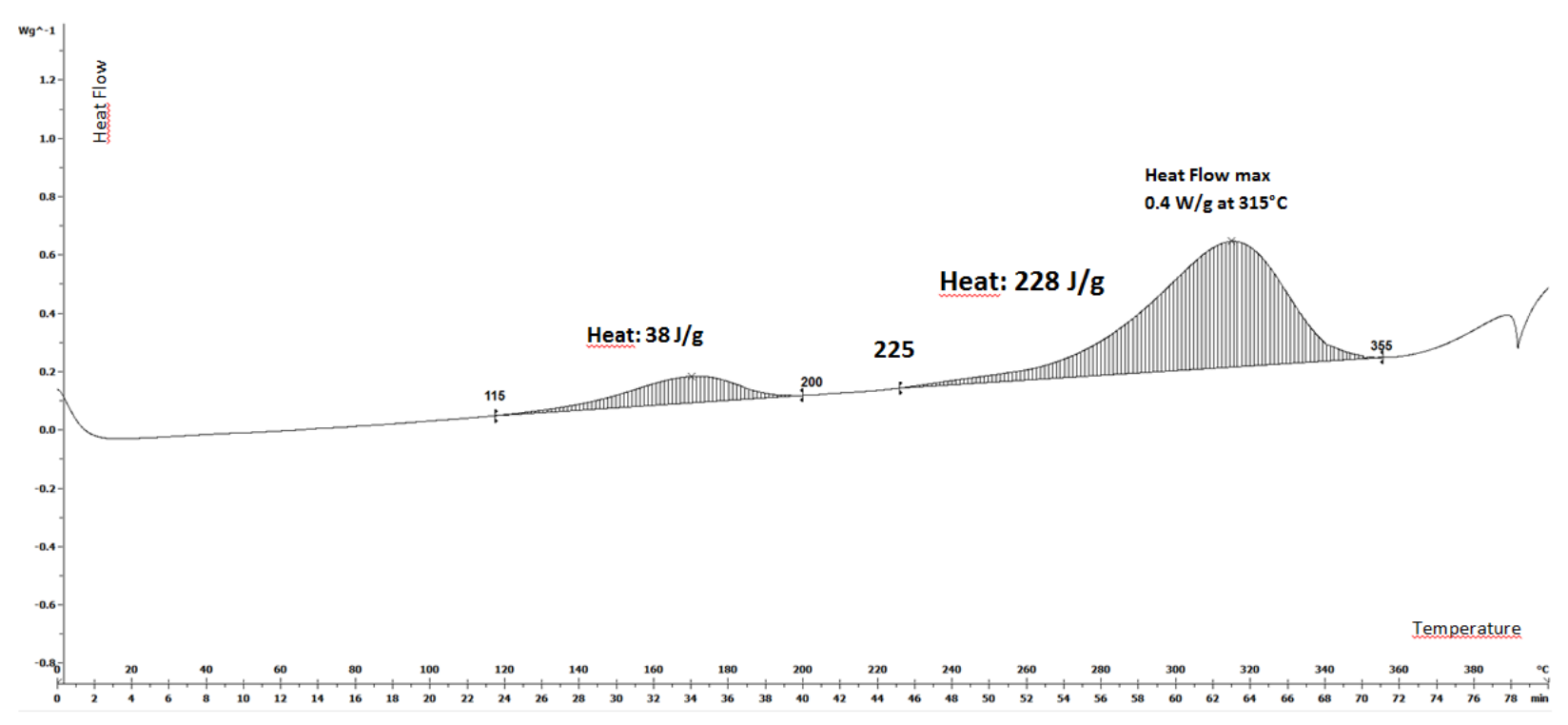

Figure 8: DSC analysis of the hydrolysis reaction medium

The DSC profile of the isolated products were also explored. It is noteworthy that both compounds 4' and $\mathbf{4}$ exhibit an autocatalytic behavior (sharp peak) with an important exothermic peak. Indeed, the $\mathrm{N}$-acetylated sulfoximine 4' decomposes with an energy exceeding $600 \mathrm{~J} / \mathrm{g}$ from $265^{\circ} \mathrm{C}$ (Figure 9). 


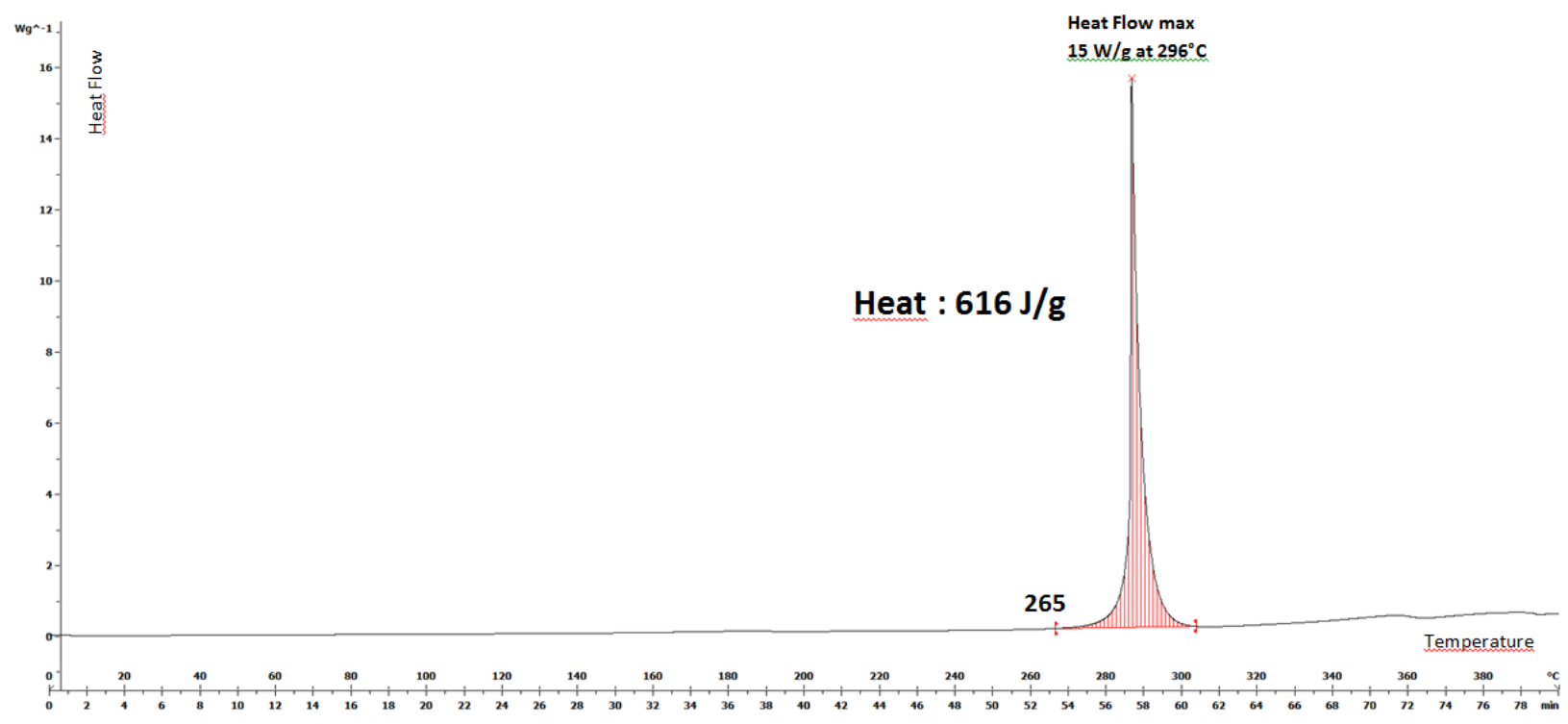

Figure 9: DSC analysis of the intermediate 4'

Similarly, the sulfoximine $\mathbf{4}$ decomposes with an exceptionally strong exothermic peak with an energy exceeding $896 \mathrm{~J} / \mathrm{g}$ from $270^{\circ} \mathrm{C}$ (Figure 10) after an endothermic peak at $48^{\circ} \mathrm{C}$ corresponding to the melting point of the compound.

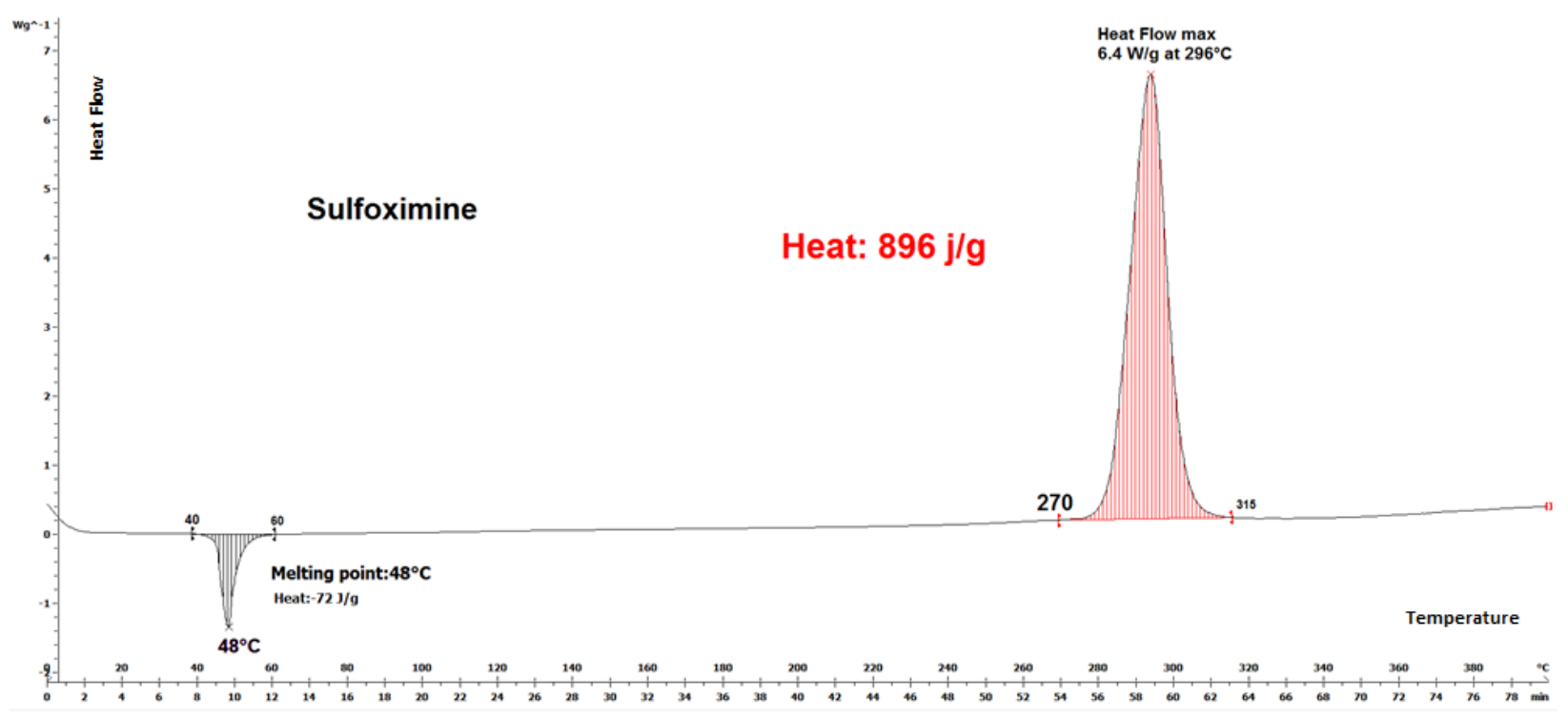

Figure 10: DSC analysis of the sulfoximine 4

\section{Synthesis of the phenyl trifluoromethyl sulfilimino iminium 5.}


In the same way as the synthesis of the sulfoximine $\mathbf{4}$, the synthesis of the sulfilimino iminium 5 starts from the trifluoromethyl sulfoxide 1, and the first step is a Ritter-type reaction between the sulfoxide $\mathbf{1}$ and acetonitrile in the presence of triflic anhydride. The major difference is the quench reagent. This time, the addition of dimethylamine delivers the desired sulfilimino iminium $\mathbf{5}$ (Scheme 5).

Scheme 5: Synthesis of the sulfilimino iminium 5
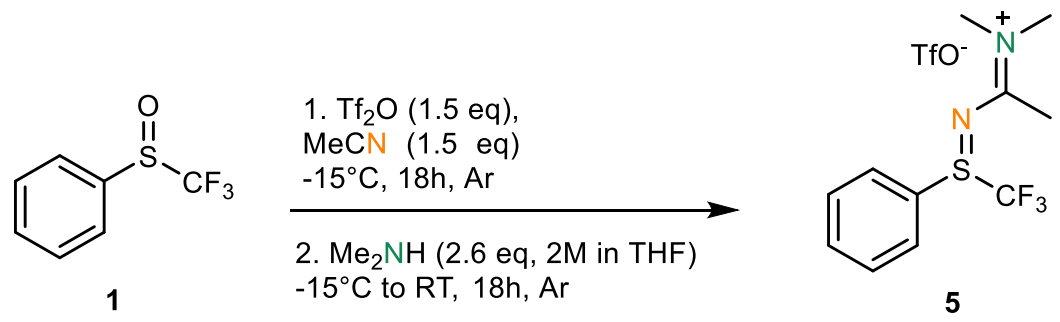

In our previous protocol, ${ }^{7 \mathrm{~b}}$ the dimethylamine was added in pure form. The use of a commercial solution of dimethylamine in THF (2M) is more convenient and was added dropwise at $-15^{\circ} \mathrm{C}$ (Table 3, entry 1). At the end of the addition, the temperature of the reaction was allowed to rise slowly to room temperature. During the scale-up of the reaction conditions, we realized that the introduction of 4 equivalents of dimethylamine led to a very dilute reaction medium, and we assumed that fewer equivalents could afford the desired product with a similar yield. When 2.6 equivalents of dimethylamine in THF are introduced, the desired sulfilimino iminium $\mathbf{5}$ is obtained with a good yield of $76 \%$ (Table 3, entry 2 ), similar to the yield with 4 equivalents (Table 3, entry 1). 
Table 3: Multigram synthesis of sulfilimino iminium 5

\begin{tabular}{ccccccc}
\hline Entry & Sulfoxide & Tf $_{2} \mathbf{O}$ & MeCN & $\begin{array}{c}\mathbf{M e}_{2} \mathbf{N H} \\
\text { in THF }\end{array}$ & Compound & Yield \\
\hline $\mathbf{1}$ & $2.0 \mathrm{~g}$ & $2.6 \mathrm{~mL}$ & $5.8 \mathrm{~mL}$ & $20.6 \mathrm{~mL} / 4 \mathrm{eq}$ & $3.0 \mathrm{~g}$ & $71 \%$ \\
$\mathbf{2}$ & $15.0 \mathrm{~g}$ & $19.5 \mathrm{~mL}$ & $43.6 \mathrm{~mL}$ & $100.0 \mathrm{~mL} / 2.6 \mathrm{eq}$ & $24.3 \mathrm{~g}$ & $76 \%$ \\
$\mathbf{3}$ & $30.0 \mathrm{~g}$ & $39.1 \mathrm{~mL}$ & $87.1 \mathrm{~mL}$ & $200.9 \mathrm{~mL} / 2.6 \mathrm{eq}$ & $40.5 \mathrm{~g}$ & $64 \%$ \\
\hline
\end{tabular}

The production of sulfilimino iminium 5 has been scaled up to $40 \mathrm{~g}$ with a good yield of $64 \%$ (Table 3, entry 3). From a practical point of view, the purification of compound 5 by chromatography on silica is quite cumbersome, using a lot of solvent and time. Changing the purification method quickly became essential during the scale-up of the synthesis. Sulfilimino iminium $\mathbf{5}$ is insoluble in diethyl ether. Therefore, compound $\mathbf{5}$ can be placed on a pad of Celite ${ }^{\circledR}$ (10 g of Celite ${ }^{\circledR}$ per gram of sulfoxide), impurities are removed by washing the Celite ${ }^{\circledR}$ with diethyl ether and the desired product is then recovered by washing the celite ${ }^{\circledR}$ with dichloromethane. If some impurities remain, the obtained solid can be washed again with diethyl ether. It is important to mention that the use of a newly opened bottle of high quality trifluoromethanesulfonic anhydride is crucial for the success of the reaction.

The thermal stability of sulfilimino iminium $\mathbf{5}$ has also been explored by DSC analysis (Figure 11). After an endothermic phenomenon corresponding to the melting of $\mathbf{5}$ around $64^{\circ} \mathrm{C}$, an exothermic peak is observed from $120^{\circ} \mathrm{C}$ with an energy at $412 \mathrm{~J} / \mathrm{g}$ revealing its good thermal stability under the process temperature. 


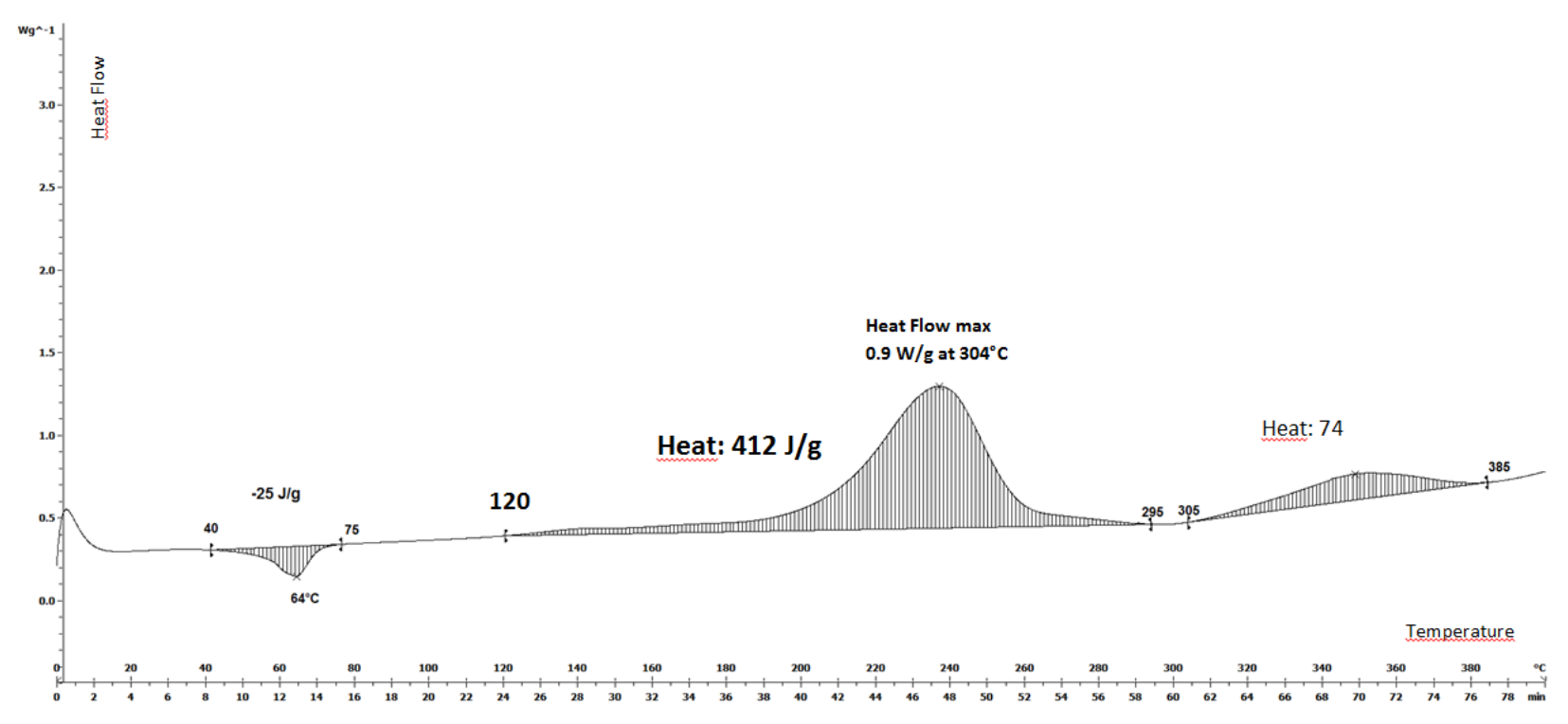

Figure 11: DSC analysis of sulfilimino iminium 4

\section{Financial estimation for reagent production.}

We have been able to produce $78 \mathrm{~g}$ of sulfoxide $1,33 \mathrm{~g}$ of sulfoximine 4 and $40.5 \mathrm{~g}$ of sufilimino iminium 5. We decided to determine the cost of the production of such batches. To estimate the cost, the reagents, the solvents used for reactions and extraction, and the solvents, Celite ${ }^{\circledR}$ or silica used for purifications have been taken into account (Tables 4, 5 and 6) but the cost of manpower has been overlooked.

Table 4: Financial estimation for the synthesis of sulfoxide 1

\begin{tabular}{llll}
\hline Reagent & Chemicals cost & Quantity & Cost (€) \\
\hline Benzene & $20.79 € / 500 \mathrm{~mL}$ & $50 \mathrm{~mL}$ & 2.08 \\
$\mathbf{C F}_{3} \mathbf{S O}_{2} \mathbf{N a}$ & $£ 83.00 / 100 \mathrm{~g}$ & $50 \mathrm{~g}$ & $47.00^{\mathrm{b}}$ \\
$\mathbf{T f O H}$ & $193.98 € / 1 \mathrm{~kg}=590 \mathrm{~mL}$ & $176 \mathrm{~mL}$ & 57.87 \\
Dichloromethane (Extraction) & $8.10 € / 5 \mathrm{~L}$ & $300 \mathrm{~mL}$ & 0.49 \\
\hline Total cost for the production of 42 g of sulfoxide $\mathbf{1}$ & & 107.43 \\
\hline Total cost for the production of 1 g of sulfoxide $\mathbf{1}$ & & $2.56(2.91 \mathrm{~S})^{\mathrm{b}}$ \\
\hline
\end{tabular}


${ }^{a}$ Negotiated prices with chemical suppliers. ${ }^{b}$ Exchange rate on 01/21/19, 13:15 UTC.

Table 5: Financial estimation for the production of sulfoximine 4

\begin{tabular}{llll}
\hline Reagent & Chemicals cost & Quantity & Cost (€) \\
\hline Sulfoxide 1 & $2.56 € / 1 \mathrm{~g}$ & $40 \mathrm{~g}$ & 102.4 \\
Tf $\mathbf{f}_{2} \mathbf{O}$ & $£ 270.0 / 1 \mathrm{~kg}=596 \mathrm{~mL}$ & $52 \mathrm{~mL}$ & $26.61^{\mathrm{b}}$ \\
Acetonitrile & $13.70 € / 2.5 \mathrm{~L}$ & $119+344 \mathrm{~mL}$ & 2.54 \\
KMnO4 & $59.90 € / 500 \mathrm{~g}$ & $32.55 \mathrm{~g}$ & 3.90 \\
HCl 37 \% & $5.57 € / 2,5 \mathrm{~L}$ & $33.6 \mathrm{~mL}$ & 0.07 \\
Dichloromethane (Extraction) & $8.10 € / 5 \mathrm{~L}$ & $1 \mathrm{~L}$ & 1.62 \\
Silica (Purification) & $11.80 € / 1 \mathrm{~kg}$ & $200 \mathrm{~g}$ & 2.36 \\
Petroleum ether (Purification) & $8.35 € / 5 \mathrm{~L}$ & $2.1 \mathrm{~L}$ & 3.51 \\
Ethyl acetate (Purification) & $10.0 € / 5 \mathrm{~L}$ & $0.4 \mathrm{~L}$ & 0.8
\end{tabular}

Total cost for the production of $33 \mathrm{~g}$ of sulfoximine 4

142.93

Total cost for the production of $1 \mathrm{~g}$ of sulfoximine 4

${ }^{a}$ Negotiated prices with chemical suppliers. ${ }^{b}$ Exchange rate on 01/21/19, 13:15 UTC.

Table 6: Financial estimation for the production of sulfilimino iminium 5

\begin{tabular}{llll}
\hline Reagent & Chemicals cost $^{\text {a }}$ & Quantity & Cost (€) \\
\hline Sulfoxide 1 & $2.56 € / 1 \mathrm{~g}$ & $30 \mathrm{~g}$ & 76.8 \\
Tf2 & $£ 270.0 / 1 \mathrm{~kg}=596 \mathrm{~mL}$ & $39.1 \mathrm{~mL}$ & $20.05^{\mathrm{b}}$ \\
Acetonitrile & $13.70 € / 2.5 \mathrm{~L}$ & $87.1 \mathrm{~mL}$ & 0.48 \\
Me2NH in THF (2M) & $74.00 € / 500 \mathrm{~mL}$ & $200.9 \mathrm{~mL}$ & 29.7 \\
Dichloromethane (Extraction) & $8.10 € / 5 \mathrm{~L}$ & $360 \mathrm{~mL}$ & 0.58 \\
Celite $^{\circledR}$ (Purification) & $399.00 € / 25 \mathrm{~kg}$ & $300 \mathrm{~g}$ & 4.79 \\
Diethyl ether (Purification) & $21.40 € / 5 \mathrm{~L}$ & $0.6 \mathrm{~L}$ & 2.57
\end{tabular}


$\begin{array}{llll}\text { Dichloromethane (Purification) } & 8.10 € / 5 \mathrm{~L} & 0.6 \mathrm{~L} & 0.97\end{array}$

Total cost for the production of $40.5 \mathrm{~g}$ of sulfilimino iminium $\mathbf{5}$

Total cost for the production of $1 \mathrm{~g}$ of sulfilimino iminium 5

${ }^{a}$ Negotiated prices with chemical suppliers. ${ }^{b}$ Exchange rate on 01/21/19, 13:15 UTC.

Globally, the cost per gram of these reagents is highly reasonable.

CONCLUSION

The production of sulfoxide $\mathbf{1}$, sulfoximine $\mathbf{4}$ and sulfilimino iminium $\mathbf{5}$ has been optimized and performed on a multi-gram scale. DSC analyses, performed on only a few milligrams of substance, allowed us to investigate the thermal stabilities of the intermediates and final species. It is noteworthy that we are confident that these quantities do not represent an upper limit, and that larger quantities could be obtained in good yields with such optimized conditions. Moreover, the overall costs of these reagents are highly reasonable. These efficient conditions clearly pave the way to easy syntheses of such reagents in any laboratory for further applications, and should contribute to the popularization of their use.

\section{EXPERIMENTAL SECTION}

\section{Synthesis of the ((trifluoromethyl)sulfinyl)benzene 1}

A dry $1 \mathrm{~L}$, three-necked, round-bottomed flask equipped with a thermometer and a mechanical stirrer was charged with sodium trifluoromethanesulfinate $(90 \mathrm{~g}, 0.58 \mathrm{~mol})$ and dried under vacuum for 24 hours prior to use. The flask is placed in a cold-water bath and trifluoromethanesulfonic acid $(315 \mathrm{~mL}, 3.56 \mathrm{~mol})$ is added, under argon, in three portions with vigorous stirring (around $100 \mathrm{~mL}$ each), in order to keep the temperature under $50^{\circ} \mathrm{C}$. After the addition, the reaction is stirred for 20-30 minutes until the temperature decreases to room temperature. Then, benzene $(90 \mathrm{~mL}, 1.01 \mathrm{~mol})$ is added in one portion and the solution is stirred at room temperature for $19 \mathrm{~h}$ under an inert atmosphere. The reaction is quenched by pouring the 
reaction medium on ice $(900 \mathrm{~g})$, extracted with dichloromethane $(3 \times 100 \mathrm{~mL})$, and washed with a saturated solution of $\mathrm{NaHCO}_{3}(3 \times 60 \mathrm{~mL})$. The organic phase is dried over $\mathrm{MgSO}_{4}$, filtered and concentrated under reduced pressure. The product is purified by distillation under reduced pressure $\left(78-80^{\circ} \mathrm{C}\right.$ at $\left.15 \mathrm{mmHg}\right)$ to afford $1(78.1 \mathrm{~g}, 73 \%$, colorless oil).

${ }^{1} \mathrm{H}$ NMR $\left(300 \mathrm{MHz}, \mathrm{CDCl}_{3}\right) \delta(\mathrm{ppm}): 7.76(\mathrm{~d}, J=7.4 \mathrm{~Hz}, 2 \mathrm{H}), 7.70-7.49(\mathrm{~m}, 3 \mathrm{H}) .{ }^{13} \mathrm{C} \mathrm{NMR}(75$ $\left.\mathrm{MHz}, \mathrm{CDCl}_{3}\right) \delta(\mathrm{ppm}): 135.6(\mathrm{q}, J=1.72 \mathrm{~Hz}), 133.6,129.61,125.9,124.7\left(\mathrm{q}, J=335 \mathrm{~Hz}, \mathrm{CF}_{3}\right)$. ${ }^{19} \mathrm{~F} \mathrm{NMR}\left(282 \mathrm{MHz}, \mathrm{CDCl}_{3}\right) \delta(\mathrm{ppm}):-75.0(\mathrm{~s}, 3 \mathrm{~F})$.

\section{Imino(phenyl)(trifluoromethyl)- $\lambda^{6}$-sulfanone 4}

In a dry $500 \mathrm{~mL}$ two-necked round-bottomed flask equipped with a dropping-funnel and a thermometer, a solution of phenyl trifluoromethyl sulfoxide 1 (40 g, $206.0 \mathrm{mmol}$ ) in dry acetonitrile $(120 \mathrm{~mL}, 2.28 \mathrm{~mol})$ is cooled to $-15^{\circ} \mathrm{C}$ under argon. $\mathrm{Tf}_{2} \mathrm{O}(52 \mathrm{~mL}, 309.1 \mathrm{mmol})$ is introduced into the dropping-funnel and added dropwise to the solution, keeping the temperature around $-15^{\circ} \mathrm{C}$. The solution is then left at $-15^{\circ} \mathrm{C}$ for $18 \mathrm{~h}$ under argon in a freezer. The reaction is quenched by pouring the reaction media on ice $(400 \mathrm{~g})$, extracted with dichloromethane ( $3 \times 80$ $\mathrm{mL})$, and washed with a saturated solution of $\mathrm{NaHCO}_{3}(3 \times 40 \mathrm{~mL})$. The organic phase is dried over $\mathrm{MgSO}_{4}$, filtered and concentrated under reduced pressure.

To a solution of this crude product in acetonitrile $(160 \mathrm{~mL})$ and water $(40 \mathrm{~mL})$ is added $\mathrm{KMnO}_{4}$ (32.56 $\mathrm{g}, 206.0 \mathrm{mmol})$ portion wise. The reaction is stirred at room temperature for 18 hours, diluted with $\mathrm{H}_{2} \mathrm{O}(150 \mathrm{~mL})$ and a saturated solution of $\mathrm{Na}_{2} \mathrm{~S}_{2} \mathrm{O}_{4}$ is added until complete discoloration of the solution. The product is extracted with dichloromethane $(3 \times 70 \mathrm{~mL})$, and the organic phase is dried over $\mathrm{MgSO}_{4}$, filtered and concentrated under reduced pressure.

The crude product is dissolved in acetonitrile $(184 \mathrm{~mL})$ and $\mathrm{HCl} 6 \mathrm{M}(67.2 \mathrm{~mL})$ is added. The reaction is stirred at room temperature for $18 \mathrm{~h}$. Then, water $(100 \mathrm{~mL})$ is added and the organic 
phase is extracted with dichloromethane $(3 \times 50 \mathrm{~mL})$, washed with a solution of saturated $\mathrm{NaHCO}_{3}$ ( $3 \times 20 \mathrm{~mL}$ ), dried over $\mathrm{MgSO}_{4}$, filtered and concentrated under reduced pressure. The product is filtered on silica (200 g) using petroleum ether/ethyl acetate $8 / 2$ as eluent to afford the desired sulfoximine 4 (32.8 g, $76 \%$, white solid).

${ }^{1} \mathrm{H}$ NMR $\left(300 \mathrm{MHz}, \mathrm{CDCl}_{3}\right) \delta(\mathrm{ppm}): 8.15(\mathrm{~d}, J=7.5 \mathrm{~Hz}, 2 \mathrm{H}), 7.84-7.72(\mathrm{~m}, 1 \mathrm{H}), 7.63(\mathrm{dd}, J=$ 8.5, 7.1 Hz, 2H), 3.53 (s, br s, 1H). ${ }^{13} \mathrm{C}$ NMR (75 MHz, $\left.\mathrm{CDCl}_{3}\right) \delta(\mathrm{ppm}): 135.6,131.6,130.7$, 129.6, $121.0\left(\mathrm{q}, J=333 \mathrm{~Hz}, \mathrm{CF}_{3}\right) .{ }^{19} \mathrm{~F} \mathrm{NMR}\left(282 \mathrm{MHz}, \mathrm{CDCl}_{3}\right) \delta(\mathrm{ppm}):-70.3(\mathrm{~s}, 3 \mathrm{~F})$.

(Z)- $N$-methyl- $N$-(1-((phenyl(trifluoromethyl)- $\lambda^{4}$-sulfanylidene)amino)ethylidene)methaneminium 5

In a dry $500 \mathrm{~mL}$ two-necked round-bottomed flask equipped with a dropping-funnel and a thermometer, under argon, a solution of phenyl trifluoromethyl sulfoxide $\mathbf{1}(30 \mathrm{~g}, 154.5 \mathrm{mmol})$ in dry acetonitrile $(87.1 \mathrm{~mL}, 1.67 \mathrm{~mol})$ is cooled to $-15^{\circ} \mathrm{C} . \mathrm{Tf}_{2} \mathrm{O}(39.1 \mathrm{~mL}, 232.4 \mathrm{mmol})$ is added dropwise, keeping the temperature around $-15^{\circ} \mathrm{C}$. The solution is then left at $-15^{\circ} \mathrm{C}$ for $18 \mathrm{~h}$ under argon in a freezer. A solution of $\mathrm{Me}_{2} \mathrm{NH}(2 \mathrm{M}$ in THF, $200.9 \mathrm{~mL}, 401.8 \mathrm{mmol})$ is added dropwise to the reaction, keeping the temperature at around $-15^{\circ} \mathrm{C}$, under an inert atmosphere. Then, the reaction mixture is allowed to warm to room temperature slowly. The reaction is stirred at room temperature for $18 \mathrm{~h}$, under an inert atmosphere. The reaction is quenched by addition of $100 \mathrm{~mL}$ of water and the product is extracted with dichloromethane $(3 \times 120 \mathrm{~mL})$. The organic phase is dried over $\mathrm{MgSO}_{4}$, filtered and concentrated under reduced pressure. The crude residue is placed on Celite ${ }^{\circledR}(300 \mathrm{~g})$ and the solid is washed three times with diethyl ether to remove impurities. Then, the deposit is washed three times with dichloromethane to recover the desired product 5 (40.5 g, $64 \%$, brownish solid). 
${ }^{1} \mathrm{H}$ NMR (300 MHz, $\left.\mathrm{CDCl}_{3}\right) \delta(\mathrm{ppm}): 8.07(\mathrm{~d}, J=7.9 \mathrm{~Hz}, 2 \mathrm{H}), 7.89-7.75(\mathrm{~m}, 1 \mathrm{H}), 7.70(\mathrm{dd}, J=$ 8.3, $6.8 \mathrm{~Hz}, 2 \mathrm{H}), 3.39$ (s, 3H), 3.35 (s, 3H), 2.67 (s, 3H). ${ }^{13} \mathrm{C} \mathrm{NMR}\left(75 \mathrm{MHz}, \mathrm{CDCl}_{3}\right) \delta(\mathrm{ppm})$ : 174.2, 135.9, 130.8, 129.2, 124.7, $123.3\left(\mathrm{q}, J=127 \mathrm{~Hz}, \mathrm{CF}_{3}\right), 120.7$ (q, $\left.J=320, \mathrm{CF}_{3}\right), 41.7,40.0$, 19.5. ${ }^{19} \mathrm{~F}$ NMR (282 MHz, $\left.\mathrm{CDCl}_{3}\right) \delta(\mathrm{ppm}):-67.4$ (s, 3F), -79.0 (s, 3F, OTf).

Experimental conditions for DSC: DSC analysis were performed in a gold-plated closed crucible high pressure $40 \mu \mathrm{L}$ Mettler, under air, applying a heating rate of $5 \mathrm{~K} / \mathrm{min}$ in the range $0 \mathrm{~K}$ to 400 $\mathrm{K} / \mathrm{min}$.

\section{Supporting Information}

NMR Spectra of the compounds 1,4 and 5 are provided.

\section{Author Contributions}

The manuscript was written through contributions of all authors. All authors have given approval to the final version of the manuscript.

\section{ACKNOWLEDGMENT}

We thank the CNRS and French Ministry of Research for their financial support. We also acknowledge Dr. Karen Wright for the careful reading and improvement of the English, Dr. F. Metz from Solvay-Rhodia Lyon for the gift of chemicals and the French Fluorine Network for its support.

\section{REFERENCES}

(1) (a) Kirsch, P. Modern Fluoroorganic Chemistry: Synthesis, Reactivity, Applications, $2^{\text {nd }}$, Completely Revised and Enlarged Edition; Wiley: New-York, 2013. (b) Müller, K.; Faeh, C.;

Diederich, F.; Fluorine in pharmaceuticals: looking beyond intuition, Science 2007, 317, 1881- 
1886. (c) Bioorganic and Medicinal Chemistry of Fluorine (Eds.: Bégué, J.-P.; Bonnet-Delpon, D.), Wiley, Hoboken, 2008. (d) Purser, S.; Moore, P. R.; Swallow, S.; Gouverneur, V. ; Fluorine in medicinal chemistry, Chem. Soc. Rev. 2008, 37, 320-330. (e) Wang, J.; Sanchez-Rosello, M.; Acena, J. L.; del Pozo, C.; Sorochinsky, A. E.; Fustero, S.; Soloshonok, V. A.; Liu, H.; Fluorine in Pharmaceutical Industry: Fluorine-containing drugs introduced to the market in the last decade (2001-2011), Chem. Rev. 2014, 114, 2432-2506.

(2) (a) O'Hagan, D.; Fluorine in health care: organofluorine containing blockbuster drugs, $J$. Fluorine Chem. 2010, 131, 1071-1081; (b) Fujiwara, T.; O'Hagan, D.; Successful fluorinecontaining herbicide agrochemicals, J. Fluorine Chem. 2014, 167, 16-29; (c) Purser, S.; Moore, P. R.; Swallowb, S.; Gouverneur, V.; Fluorine in medicinal chemistry, Chem. Soc Rev. 2008, 37, 320330.

(3) O’Hagan, D.; Harper, D. B.; Fluorine-containing natural products, J. Fluorine Chem. 1999, 100, 127-133.

(4) (a) Ni, C.; Hu, M.; Hu, J.; Good partnership between sulfur and fluorine: sulfur-based fluorination and fluoroalkylation reagents for organic synthesis, Chem. Rev. 2015, 115, 765-825; (b) Charpentier, J; Früh, N.; Togni, A.; Electrophilic trifluoromethylation by use of hypervalent iodine reagents, Chem. Rev. 2015, 115, 650-682.

(5) For reviews see: a) Bizet, V.; Kowalczyk, R.; Bolm, C. Fluorinated sulfoximines: syntheses, properties and applications, Chem. Soc. Rev. 2014, 43, 2426-2438; b) Shen, X.; Hu, J.; Fluorinated sulfoximines: preparation, reactions and applications, Eur. J. Org. Chem. 2014, 4437-4451; c) Barthelemy, A.-L.; Magnier, E. Recent trends in perfluorinated sulfoximines, C. R. Chimie 2018, $21,711-722$.

(6) Daniel, M.; Dagousset, G.; Diter, P.; Klein, P.-A.; Tuccio, B.; Goncalves, A.-M.; Masson, G.; Magnier, E.; Fluorinated sulfilimino iminiums: efficient and versatile sources of perfluoroalkyl radicals under photoredox catalysis, Angew. Chem. Int. Ed., 2017, 56, 3997-4001. 
(7) (a) Mace, Y.; Urban, C.; Pradet, C.; Marrot, J.; Blazejewski, J.-C.; Magnier, E. ; Sulfilimines and sulfoximines by reaction of nitriles with perfluoroalkylsulfoxides, Eur. J. Org. Chem. 2009, 3150-3153; (b) Urban, C.; Mace, Y.; Cadoret, F.; Blazejewski, J.-C.; Magnier, E.; Divergent preparation of fluoroalkylated sulfilimine and sulfilimino iminium salts, Adv. Synth. Catal. 2010, 352, 2805-2814; (c) Urban, C.; Cadoret, F.; Blazejewski, J.-C.; Magnier, E.; Sulfoximines as a Versatile Scaffold for Electrophilic Fluoroalkylating Reagents, Eur. J. Org. Chem. 2011, 48624867; (d) Pégot, B.; Urban, C.; Diter, P.; Magnier, E.; Perfluoroalkylated Bis (sulfilimine) s and Bis (sulfoximine) s by a Ritter-Type Reaction, Eur. J. Org. Chem. 2013, 7800-7808; (e) Pegot, B.; Urban, C.; Bourne, A.; Le, T.-N.; Bouvet, S.; Marrot, J.; Diter, P.; Magnier, E. ; Difluoromethyl and chlorofluoromethyl sulfoximines: synthesis and evaluation as electrophilic perfluoroalkylating reagents, Eur. J. Org. Chem. 2015, 3069-3075.

(8) Magnier, E.; Blazejewski, J.-C.; Tordeux, M.; Wakselman, C.; Straightforward one-pot synthesis of trifluoromethyl sulfonium salts, Angew. Chem. Int. Ed. 2006, 45, 1279-1282. 